Article

\title{
Sustainable Ship Loading Planning for Prefabricated Products in the Construction Industry
}

\author{
Wen Yi ${ }^{1, *}$, Robyn Phipps ${ }^{1}$ and Hans Wang ${ }^{2}$ \\ 1 School of Built Environment, College of Sciences, Massey University, 0632 Auckland, New Zealand; \\ R.A.Phipps@massey.ac.nz \\ 2 Faculty of Business, The Hong Kong Polytechnic University, Hong Kong SAR, China; \\ h.wang20190216@gmail.com \\ * Correspondence: wenyi0906@gmail.com; Tel.: +64-9-414-0800
}

Received: 16 September 2020; Accepted: 13 October 2020; Published: 27 October 2020

\begin{abstract}
This paper focuses on sustainable transportation of prefab products from factories to construction sites by ship. Since the transportation cost for all the prefab products of a construction site is mainly dependent on the number of cargo holds used on ships, a loading plan for prefab products that minimizes the number of holds required is highly desirable. This paper is therefore devoted to the development of an optimal loading plan that decides which prefab products are loaded into each cargo hold and how to pack these prefab products into the holds so that as few holds as possible are used. We formulate the problem as a large-scale integer optimization model whose objective function is to minimize the total number of cargo holds used and whose constraints represent the cargo hold capacity limits. We develop a heuristic to solve the problem and obtain a high-quality solution. We have tested the model and algorithm on a case study that includes 20 prefab products. We find that different cargo holds carry prefab products that have quite different densities. Moreover, the orientations of many prefab products are different from their default orientations. The results demonstrate the applicability of the proposed model and algorithm.
\end{abstract}

Keywords: sustainable shipping; logistics in construction; prefabrication product loading plan

\section{Introduction}

The construction industry has a long history [1]. Over the years, the industry has been striving to develop new techniques, methods, and tools to improve safety, productivity, and quality and to reduce the cost of construction [2]. Prefabrication is one such method [3-6]. As far back as the Empire State Building, built in 1931, the use of off-site prefabrication was common with "just in time" delivery to the site only when installation was ready to accept the component. The supply chain and logistics practices have advanced today but the idea is essentially the same-build as many components off-site as possible, where conditions can be controlled, and use the site as an assembly location [7].

The conventional method of construction is to transport bricks, timber, sand, etc. to construction site and then to construct a building from the materials. In prefabricated construction, the foundation of a building is generally built using conventional construction methods and walls, floors, and roofs are generally prefabricated in a factory and transported to the construction site for assembly. Prefabricated products (prefab products) can be small components, 2D panels, 3D modules, a mixture of the above, or a complete building. The prefab products are manufactured in factories, similar to products in the traditional manufacturing industry. They are then transported, usually by cargo hold, to construction sites. At the construction sites, the prefab products are installed and assembled. The motivation for prefabrication construction is to group similar construction tasks to allow workers to work on similar tasks multiple times and to improve efficiency. Moreover, when the construction tasks are conducted in a 
factory, the management of resources, scheduling, and quality control can be well planned. It is generally accepted that prefabrication has the advantages of lower cost, higher productivity, higher quality, eliminating impact of weather on construction, no expensive on-site falsework, and improved worker health and safety. However, prefabrication has a few disadvantages. The first one is there are limited varieties of styles of buildings, though mass customization is an option. The second one is the transportation costs are higher for voluminous prefabs than for their constituent materials because the materials can be packed more densely; Hong et al. [8] reported that transportation cost accounts for $10 \%$ of the cost of typical prefabricated components. This paper focuses on the transportation of prefab products from factories to construction sites by ship. In traditional construction processes, loose construction materials such as sand, bricks, and cement are transported to construction sites. Since the granularity of these materials is small, they can be tightly packed in a cargo hold when they are transported. In prefab construction processes, the size and weight of a piece of prefab product are significant. Since the transportation cost for all the prefab products of a construction site is mainly dependent on the number of cargo holds used, a loading plan for prefab products that minimizes the number of cargo holds required is highly desirable. This paper is therefore devoted to the development of an optimal loading plan that decides which prefab products are loaded into one cargo hold and how to pack these prefab products in the cargo hold so that the least number of cargo holds are used while the volume and weight capacities of cargo holds are satisfied. The party that is directly in charge of the loading and transportation will benefit from our research and the benefit can be shared among several parties in the supply chain. If the prefab factory is in charge of the loading and transportation, that is, the prices of prefab products already include the costs of the transportation, then the prefab factory can use our research to reduce its cost. If a logistics company is in charge of the loading and transportation, it can use our model to reduce the number of cargo holds used and therefore to charge a lower price to the customer. Optimizing the number of loads per cargo hold can reduce the number of cargo holds on the road, and therefore the fossil fuels used and emissions generated from transportation.

\subsection{Literature Review}

The first type of relevant studies is those looking at adoption of prefabrication in construction. Chen et al. [9] found that whether a construction project employs prefab largely depends on the familiarity and personal preference of the decision maker. They therefore proposed a construction method selection model to assist decision makers to evaluate the pros and cons for prefabrication compared with the conventional construction method. Li et al. [10] collected prefabrication housing production data based on a literature review, regulations, expert interviews, and government reports and then performed a strengths, weaknesses, opportunities, and threats (SWOT) analysis for prefab residential housing in Hong Kong. Chang et al. [11] argued that in the fast urbanization process in China, adopting prefabrication construction allows the governments, prefab housing producers, and contractors to be more sustainable. Lu et al. [12] developed a methodological framework to identify the optimal level of prefabrication adoption under different political, economic, social, and technological contexts. The framework's applicability is demonstrated using a case study in Hong Kong. Zhang et al. [13] collected 22 hindrances of adopting prefabrication in the literature. Based on a questionnaire survey and face-to-face interviews, they identified the most significant hindrances.

The second type of relevant studies considers measures to improve prefabrication-based construction. Tam et al. [14] conducted questionnaire surveys and structured interviews and discovered that involving contractors and subcontractors in the design stage can bring advantages because subcontractors often lack experience in using prefabrication. Tam et al. [15] conducted two case studies to uncover the best practice of prefabrication construction in Hong Kong. Li et al. [16] employed simulation and identified a few scheduling risks when prefabrication housing production is moved offshore, including incompatibility between different companies' information systems, logistics information errors, delay of delivery of prefabs, and design information gaps between designer and manufacturer. 
Li et al. [17] developed a simulation game to train practitioners in prefab construction. The results show that the game can considerably improve practitioners' understanding of knowledge concepts in prefab. Wong et al. [18] conducted semi-structured interviews of Australian construction site managers regarding their intention to use prefabrication. The results demonstrated that the managers were aware of the need and importance of using prefabrication but not yet well-prepared. Chen et al. [19] developed a physical internet-enabled building information modeling system (PI-BIMS) for prefabrication construction. The system enables real-time data collection, information flow, and visualization along the whole process of production, transportation, and on-site assembly of prefab products. Li et al. [20] developed an internet of things (IoT)-enabled platform to provide decision support to different stakeholders in prefabrication construction, aimed at improving efficiency in daily operations and communication. Li et al. [21] integrated system dynamics and discrete event simulation to analyze the schedule design of a prefab construction site in Hong Kong. Key reasons for schedule design were identified, some of which can lead to delays of more than five hours. Liu and $\mathrm{Lu}$ [22] developed a dual-level multiproject scheduling framework to optimize resource allocation in prefabrication projects. The effectiveness of the proposed framework was demonstrated through a case study. Tan et al. [23] conducted a questionnaire survey regarding barriers affecting China's application of BIM to prefabricated construction. They found that cost, lack of research on BIM in China, and the absence of government standards are the three key hindrances.

The third type of relevant studies is those on the logistics chain of prefab products. The logistics chain of prefab products is similar to the manufacturing, transportation, and assembly process of industry products. Tommelein and $\mathrm{Li}$ [24] examined the delivery of ready-mix concrete to construction sites in a just-in-time manner, either by a batch plant or by the contractor's own revolving-drum cargo hold. They found that which just-in-time approach is preferable depends on the contractor's willingness to control and the variability in the contractor's demand for ready-mix concrete. Pheng and Chuan [25] conducted surveys and interviews regarding factors that affect contractors' adoption of just-in-time delivery of precast concrete components. They found that contractors in general overlooked the benefits of just-in-time delivery of prefab products in terms of alleviating traffic congestion and reducing storage space in construction sites. Li et al. [10] applied a social network analysis method to recognize stakeholder-associated risk factors in prefabrication housing construction projects. They proposed BIM to facilitate communication between stakeholders and thereby to alleviate stakeholder-associated risks. Niu et al. [26] developed a smart construction objects (SCOs)-enabled system that enhances concurrence of process and the flow of information to improve the logistics in prefabrication construction. Hsu et al. [27] analyzed the logistics chain of prefab products and developed a stochastic optimization model for prefab production scheduling and inventory management. There are also studies on road transport [28-31] and maritime transport [32-34], but these studies do not examine the packing of cargoes onto the vehicles/vessels.

Based on the literature review, we find a gap in that no study has been devoted to the load planning for prefab products in cargo holds. To bridge the gap, we employed mathematical models and optimization methods to address this practical problem for construction. We enriched the literature by applying an optimization solution approach to prefabricated construction process.

\subsection{Objectives and Contributions}

The objective of this research is to propose an optimization model for prefab product load planning to minimize the number of cargo holds required to transport them. The contribution of the paper is twofold. First, to the best of our knowledge, we are the first to propose the prefab product load planning problem, which contributes to the literature on prefab construction. Second, we propose a heuristic that solves the problem and identifies a high-quality solution.

The remainder of the paper is organized as follows: Section 2 presents the problem statement and model. Section 3 proposes the solution method. Section 4 reports the results of a case study. Section 5 presents discussions and points out future research opportunities. Section 6 concludes. 


\section{Problem Description and Mathematical Model}

A construction site requires a total of $N$ prefabricated products transported from a factory. Define set $I=\{1, \ldots, N\}$. Prefab product $i \in I$ is treated as a rectangular prism, with the sizes of $a_{i}, b_{i}$, and $c_{i}$ in the three dimensions. Each prefab product has a weight $w_{i}$. We assume that all the prefab products are manufactured in the same factory; otherwise we can optimize the packing of prefab products for each factory separately. We further assume that all the prefab products are to be transported from the factory to the construction site on the same day. If the construction site is not large enough to temporarily store all the prefab products and/or the prefab products are to be transported on different days, we can optimize the packing of prefab products for each day separately.

We assume that the prefab products are transported by homogeneous cargo holds. The sizes of a cargo hold in the three dimensions are $A, B$, and $C$; for simplicity, the three dimensions of a cargo hold are called the A-dimension, B-dimension, and C-dimension, as shown in Figure 1. The weight capacity of a cargo hold is $W$. We have $A \geq \max _{i \in I} a_{i}, B \geq \max _{i \in I} b_{i}, C \geq \max _{i \in I} c_{i}, W \geq \max _{i \in I} w_{i}$, We try to load all the prefab products into as few cargo holds as possible. Note that if the cargo holds are heterogeneous, the proposed model and algorithm in the paper are still applicable after minimal revision.

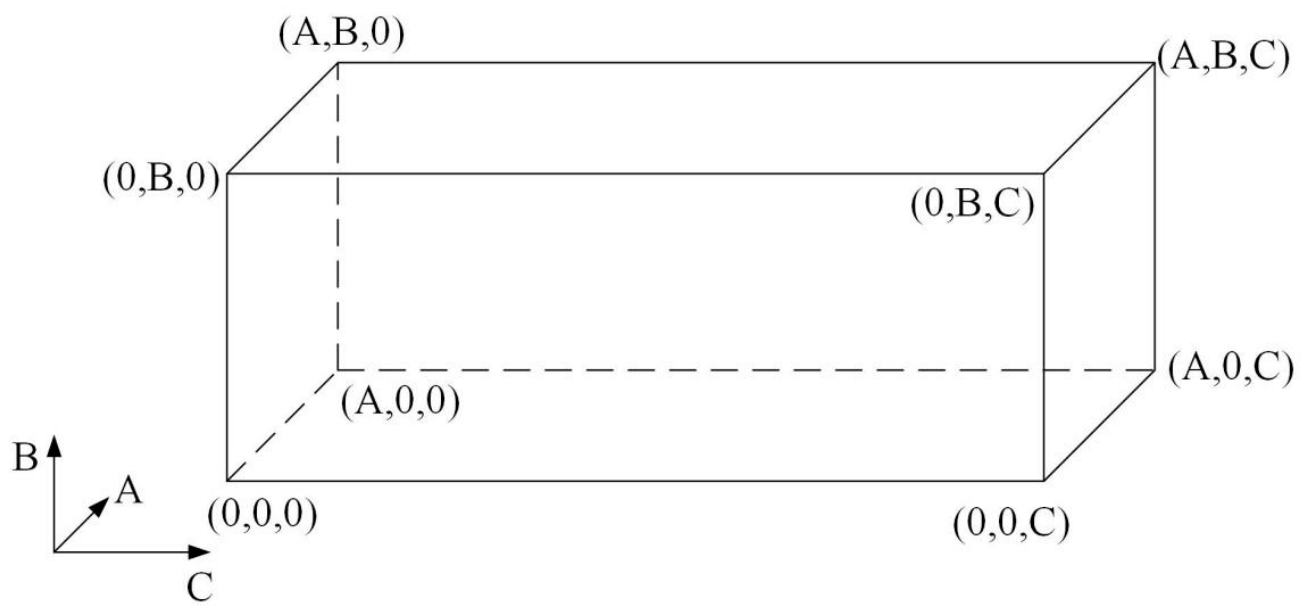

Figure 1. Coordinate system for cargo holds.

A lower bound on the number of cargo holds required is denoted by $K_{1}=\max \left\{\left\lceil\frac{\sum_{i \in I} a_{i} b_{i} c_{i}}{A B C}\right],\left\lceil\frac{\sum_{i \in E} w_{i}}{W}\right\rceil\right\}$, where $\lceil x\rceil$ returns the smallest integer greater than or equal to $x$. An upper bound on the number of cargo holds required is denoted by $K_{2}=N$, that is, each cargo hold carries only one prefab product. The minimum number of cargo holds required is between $K_{1}$ and $K_{2}$.

The decision variables in our model are summarized in Table 1 . They can be classified into a few categories: the decision variables $t_{k}$ determine the number of cargo holds used to transport all the prefab products; the decision variables $z_{i k}$ are on the assignment of prefab products to cargo holds; the decision variables $y_{i 1}, y_{i 2}, y_{i 3}, y_{i 4}, y_{i 5}$, and $y_{i 6}$ determine the orientation of a prefab product on a cargo hold; the decision variables $d_{i 1}, d_{i 2}$, and $d_{i 3}$ determine, based on the orientation of a prefab product, its sizes in the three dimensions; the decision variables $x_{i 1}, x_{i 2}$, and $x_{i 3}$ determine the location of a prefab product in a cargo hold. 
Table 1. Decision variables.

\begin{tabular}{|c|c|}
\hline Symbol & Meaning \\
\hline$t_{k}$ & Binary variable that is equal to 1 if cargo hold $k=1, \ldots, K_{2}$ is used and 0 otherwise \\
\hline$z_{i k}$ & $\begin{array}{l}\text { Binary variable that is equal to } 1 \text { if prefab product } i \in I \text { is loaded into cargo hold } \\
\qquad k=1, \ldots, K_{2} \text { and } 0 \text { otherwise }\end{array}$ \\
\hline$y_{i 1}$ & $\begin{array}{l}\text { Binary variable that is equal to } 1 \text { if prefab product } i \text { is loaded into a cargo hold such that } \\
\text { the prefab product's size is } a_{i} \text { in the A-dimension, } b_{i} \text { in the B-dimension, } c_{i} \text { in } \\
\text { the } \mathrm{C} \text {-dimension, and } 0 \text { otherwise }\end{array}$ \\
\hline$y_{i 2}$ & $\begin{array}{c}\text { Binary variable that is equal to } 1 \text { if prefab product } i \text { is loaded into a cargo hold such that } \\
\text { the prefab product's size is } a_{i} \text { in the A-dimension, } c_{i} \text { in the B-dimension, } b_{i} \text { in } \\
\text { the } \mathrm{C} \text {-dimension, and } 0 \text { otherwise }\end{array}$ \\
\hline$y_{i 3}$ & $\begin{array}{l}\text { Binary variable that is equal to } 1 \text { if prefab product } i \text { is loaded into a cargo hold such that } \\
\text { the prefab product's size is } b_{i} \text { in the A-dimension, } a_{i} \text { in the B-dimension, } c_{i} \text { in } \\
\text { the } \mathrm{C} \text {-dimension, and } 0 \text { otherwise }\end{array}$ \\
\hline$y_{i 4}$ & $\begin{array}{l}\text { Binary variable that is equal to } 1 \text { if prefab product } i \text { is loaded into a cargo hold such that } \\
\text { the prefab product's size is } b_{i} \text { in the A-dimension, } c_{i} \text { in the B-dimension, } a_{i} \text { in } \\
\text { the } \mathrm{C} \text {-dimension, and } 0 \text { otherwise }\end{array}$ \\
\hline$y_{i 5}$ & $\begin{array}{c}\text { Binary variable that is equal to } 1 \text { if prefab product } i \text { is loaded into a cargo hold such that } \\
\text { the prefab product's size is } c_{i} \text { in the A-dimension, } a_{i} \text { in the B-dimension, } b_{i} \text { in } \\
\text { the } \mathrm{C} \text {-dimension, and } 0 \text { otherwise }\end{array}$ \\
\hline$y_{i 6}$ & $\begin{array}{l}\text { Binary variable that is equal to } 1 \text { if prefab product } i \text { is loaded into a cargo hold such that } \\
\text { the prefab product's size is } c_{i} \text { in the A-dimension, } b_{i} \text { in the B-dimension, } a_{i} \text { in } \\
\text { the } \mathrm{C} \text {-dimension, and } 0 \text { otherwise }\end{array}$ \\
\hline$d_{i 1}$ & The size of the prefab product $i$ in the A-dimension of the cargo hold \\
\hline$d_{i 2}$ & The size of the prefab product $i$ in the B-dimension of the cargo hold \\
\hline$d_{i 3}$ & The size of the prefab product $i$ in the C-dimension of the cargo hold \\
\hline$x_{i 1}$ & The coordinate of the centroid of prefab product $i$ in the A-dimension of the cargo hold \\
\hline$x_{i 2}$ & The coordinate of the centroid of prefab product $i$ in the B-dimension of the cargo hold \\
\hline$x_{i 3}$ & The coordinate of the centroid of prefab product $i$ in the C-dimension of the cargo hold \\
\hline
\end{tabular}

The optimal cargo hold loading planning problem for the prefabricated products can be formulated as the following model:

(P1)

subject to

$$
\begin{gathered}
\min \sum_{k=1}^{K_{2}} t_{k} \\
t_{k} \geq z_{i k}, i \in I, k=1, \ldots, K_{2} \\
\sum_{k=1}^{K_{2}} z_{i k}=1, i \in I \\
d_{i 1}=a_{i}\left(y_{i 1}+y_{i 2}\right)+b_{i}\left(y_{i 3}+y_{i 4}\right)+c_{i}\left(y_{i 5}+y_{i 6}\right), i \in I \\
d_{i 2}=a_{i}\left(y_{i 3}+y_{i 5}\right)+b_{i}\left(y_{i 1}+y_{i 6}\right)+c_{i}\left(y_{i 2}+y_{i 4}\right), i \in I \\
d_{i 3}=a_{i}\left(y_{i 4}+y_{i 6}\right)+b_{i}\left(y_{i 2}+y_{i 5}\right)+c_{i}\left(y_{i 1}+y_{i 3}\right), i \in I \\
x_{i 1} \geq \frac{d_{i 1}}{2}, i \in I \\
x_{i 1} \leq A-\frac{d_{i 1}}{2}, i \in I \\
x_{i 2} \geq \frac{d_{i 2}}{2}, i \in I \\
x_{i 2} \leq B-\frac{d_{i 2}}{2}, i \in I
\end{gathered}
$$




$$
\begin{gathered}
x_{i 3} \geq \frac{d_{i 3}}{2}, i \in I \\
x_{i 3} \leq C-\frac{d_{i 3}}{2}, i \in I \\
\left|x_{i 1}-x_{j 1}\right| \geq \frac{d_{i 1}+d_{j 1}}{2}-M\left(2-z_{i k}-z_{j k}\right), i \in I, j \in I, i \neq j, k=1, \ldots, K_{2} \\
\left|x_{i 2}-x_{j 2}\right| \geq \frac{d_{i 2}+d_{j 2}}{2}-M\left(2-z_{i k}-z_{j k}\right), i \in I, j \in I, i \neq j, k=1, \ldots, K_{2} \\
\left|x_{i 3}-x_{j 3}\right| \geq \frac{d_{i 3}+d_{j 3}}{2}-M\left(2-z_{i k}-z_{j k}\right), i \in I, j \in I, i \neq j, k=1, \ldots, K_{2} \\
\sum_{i \in I} w_{i} z_{i k} \leq W t_{k}, k=1, \ldots, K_{2} \\
t_{k}=1, \quad k=1, \ldots, K_{1} \\
t_{k} \in\{0,1\}, \quad k=K_{1}+1, \ldots, K_{2} \\
z_{i k} \in\{0,1\}, i \in I, k=1, \ldots, K_{2} \\
y_{i 1} \in\{0,1\}, i \in I \\
y_{i 2} \in\{0,1\}, i \in I \\
y_{i 3} \in\{0,1\}, i \in I \\
y_{i 4} \in\{0,1\}, i \in I \\
y_{i 5} \in\{0,1\}, i \in I . \\
y_{i 6} \in\{0,1\}, i \in I \\
d_{i 1} \geq 0, i \in I \\
d_{i 2} \geq 0, i \in I \\
d_{i 3} \geq 0, i \in I \\
x_{i 1} \geq 0, i \in I \\
x_{i 2} \geq 0, i \in I \\
x_{i 3} \geq 0, i \in I \\
\end{gathered}
$$

The objective function (1) minimizes the total number of cargo holds used to transport the prefab products. Constraint (2) enforces the condition that a cargo hold is used as long as it transports a prefab product. Constraint (3) requires that every prefab product must be transported. Constraint (4) requires that every prefab product has exactly one orientation when loaded into a cargo hold. Constraints (5)-(7) calculate the sizes of the prefab product $i$ in the A-dimension of the cargo hold, in the B-dimension, and in the C-dimension, respectively. Constraints (8)-(13) mandate that the whole volume of a prefab product must stay within the boundary of the rectangular prism of the cargo hold. Constraints (14)-(16), in which $M$ is a big positive number, require that if two prefab products, $i$ and $j$, are loaded into the same cargo hold, $k$, then they cannot overlap with each other. Take Constraint (14) as an example. When $z_{i k}$ is 0 , or $z_{j k}$ is 0 , or both are 0 , then $2-z_{i k}-z_{j k} \geq 1$ and $M\left(2-z_{i k}-z_{j k}\right)$ is very large. As a result, Constraint (14) will not affect the values of decision variables $x_{i 1}$ and $x_{j 1}$. When both $z_{i k}$ and $z_{j k}$ are 1 , meaning that products $i$ and $j$ are loaded into the same cargo hold, $k$, then Constraint (14) will become $\left|x_{i 1}-x_{j 1}\right| \geq\left(d_{i 1}+d_{j 1}\right) / 2$, ensuring that prefab products $i$ and $j$ cannot overlap with each other in the A-dimension. Constraint (17) requires that the total weight of prefab products loaded 
into a cargo hold must not exceed the weight capacity of the cargo hold. Constraint (18) mandates that all the first $K_{1}$ cargo holds are used. Constraint (19) defines $t_{k}$ as binary variables. Constraint (20) defines $z_{i k}$ as binary variables. Constraints (21)-(26) define $y_{i 1}, \ldots, y_{i 6}$ as binary variables, respectively. Constraints (27)-(29) define $d_{i 1}, d_{i 2}$, and $d_{i 3}$ as non-negative variables, respectively. Constraints (30)-(32) define $x_{i 1}, x_{i 2}$, and $x_{i 3}$ as non-negative variables, respectively.

\section{Solution Method}

Model (P1) is challenging to solve because it has a very large number of integer decision variables [35-40]. Given a problem instance, the number of decision variables $t_{k}$ is $O(N)$, where the big-O notation is used, the number of decision variables $z_{i k}$ is $O(N \cdot|I|)$; the number of decision variables $y_{i 1}, y_{i 2}, y_{i 3}, y_{i 4}, y_{i 5}$, and $y_{i 6}$ is $O(N \cdot|I|)$; the number of decision variables $d_{i 1}, d_{i 2}$, and $d_{i 3}$ is $O(N \cdot|I|)$; the number of decision variables $x_{i 1}, x_{i 2}$, and $x_{i 3}$ is $O(N \cdot|I|)$. Therefore, the number of integer decision variables is $O(N \cdot|I|)$ and the number of continuous variables is $O(N \cdot|I|)$. As a result, it is not possible to directly solve model (P1) using off-the-shelf solvers.

To address model (P1), we propose a heuristic approach below. We first explain the main ideas behind the heuristic and then present the overall algorithm.

First, we calculate the density of each prefab product $i$ as $\rho_{i}=w_{i} /\left(a_{i} b_{i} c_{i}\right)$. We will try to balance the low-density prefab products in a cargo hold with the high-density prefab products in a cargo hold. Specifically, we will first try to load a low-density prefab product into a cargo hold, then a high-density prefab product, then another low-density prefab product, and then another high-density prefab product, etc.

Second, we try to find a location (coordinates of the centroid) and orientation of a prefab product in a cargo hold such that the volume of the occupied rectangular prism is minimum. Suppose that the set of prefab products in a cargo hold $k$ is $I_{k}, I_{k} \subseteq I$. Then the volume of the occupied rectangular prism is

$$
V\left(I_{k} ; x_{i 1}, x_{i 2}, x_{i 3}, d_{i 1}, d_{i 2}, d_{i 3}, i \in I_{k}\right)=\left(\max _{i \in I_{k}}\left\{x_{i 1}+d_{i 1} / 2\right\}\right)\left(\max _{i \in I_{k}}\left\{x_{i 2}+d_{i 2} / 2\right\}\right)\left(\max _{i \in I_{k}}\left\{x_{i 3}+d_{i 3} / 2\right\}\right) .
$$

We try to place all the prefab products into a "corner" (that is, in a way such that the volume of the occupied rectangular prism is minimum) because we can leave enough "intact" volume to load more prefab products. It should be noted that the function $V\left(I_{k} ; x_{i 1}, x_{i 2}, x_{i 3}, d_{i 1}, d_{i 2}, d_{i 3}, i \in I_{k}\right)$ is monotonically increasing with $x_{i 1}, x_{i 2}$, and $x_{i 3}$, and therefore if we find a feasible centroid for a prefab product with a particular orientation, we no longer need to try a centroid with larger coordinates for the same orientation.

Third, we try to load as many prefab products into a cargo hold as possible. Once no more prefab product can be loaded, we use a second cargo hold.

We are now ready to present the algorithm. The overall algorithm is "Algorithm 1: UseFewerTrucksHeuristic()." It calls a sub-algorithm "Algorithm 2: LoadAsManyPrefabProducts $(k, \bar{I})$, " which calls another sub-algorithm "Algorithm 3: bLoadOntoTruck $\left(i^{*}, I_{k}\right) . "$

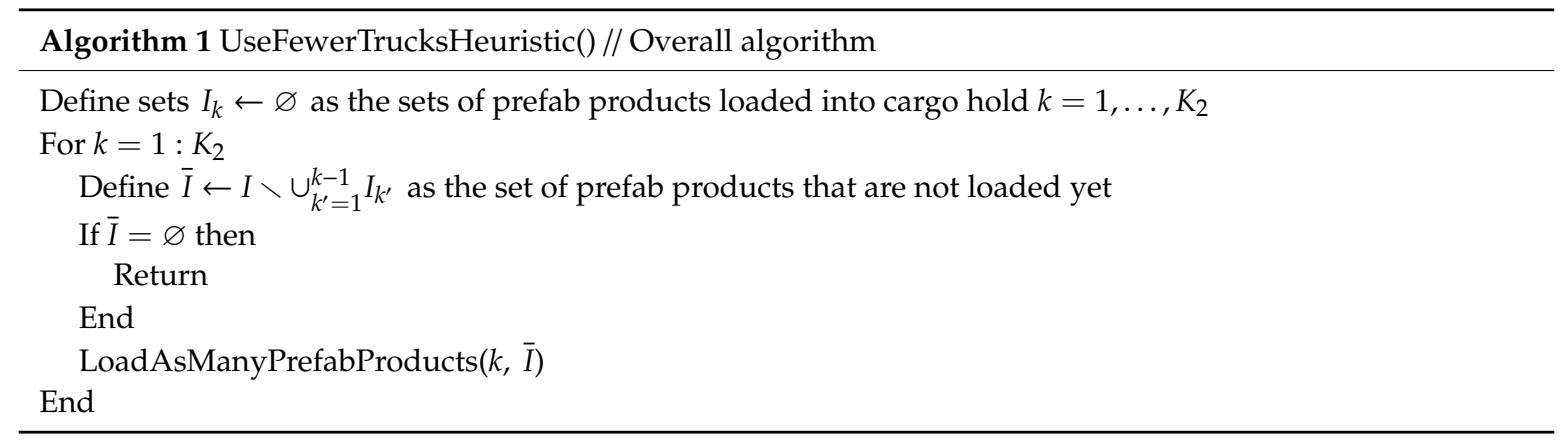




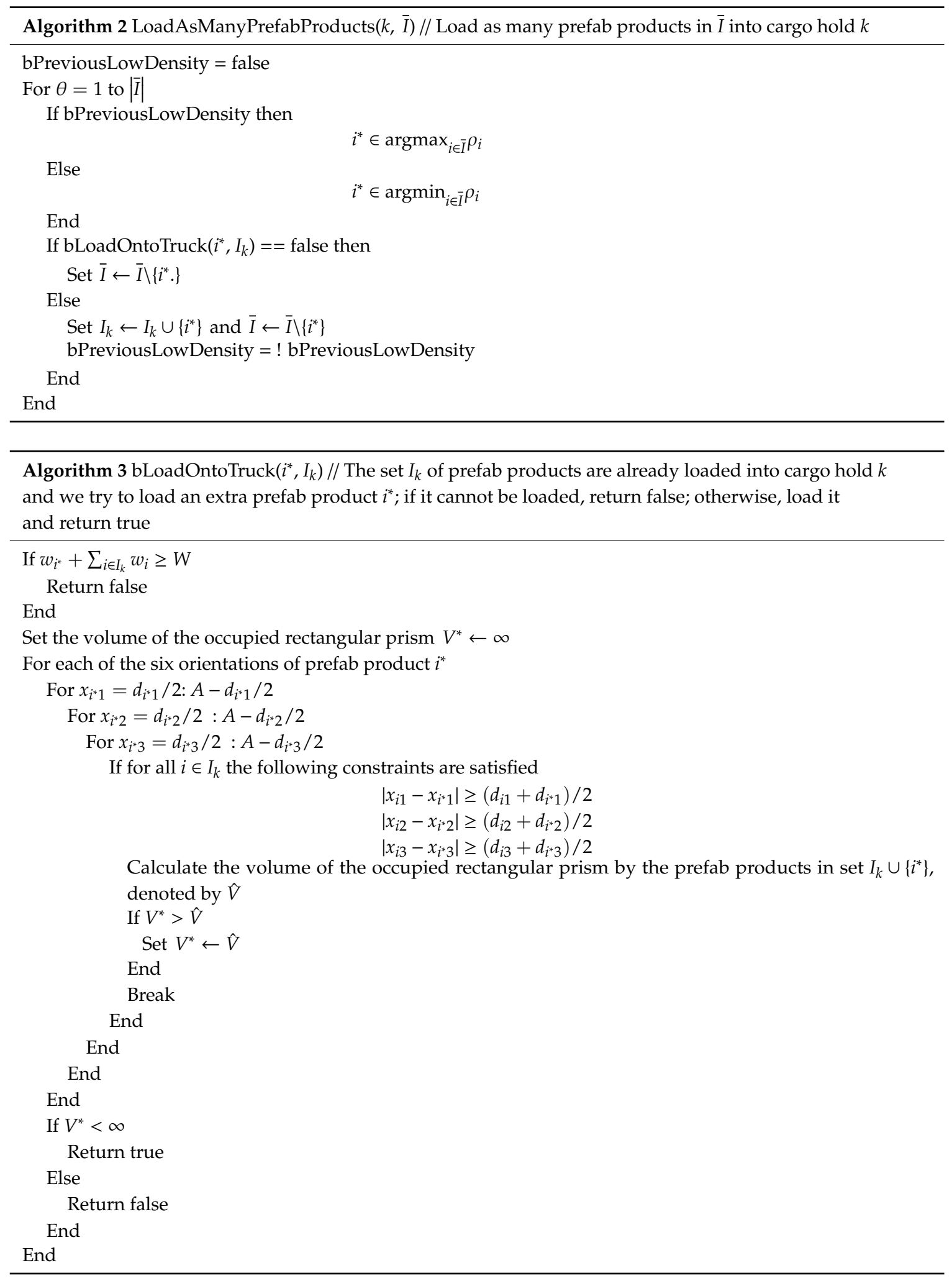

\section{Case study}

We carried out a case study to demonstrate the applicability of the proposed model and algorithm. The cargo hold has a dimension of $12.5 \times 2.4 \times 2.7 \mathrm{~m}$. We used $5 \mathrm{~cm}$ as a unit length and hence $A=48$, $B=54$, and $C=250$. The weight capacity $W=35$. We considered a total of $I=20$ prefab products, whose dimensions and weights are shown in Table 2. 
Table 2. Information of the 20 prefab products.

\begin{tabular}{cccccc}
\hline ID & $\boldsymbol{a}_{\boldsymbol{i}}$ & $\boldsymbol{b}_{\boldsymbol{i}}$ & $\boldsymbol{c}_{\boldsymbol{i}}$ & $\boldsymbol{w}_{\boldsymbol{i}}$ & $\rho_{\boldsymbol{i}}$ \\
\hline 1 & 12 & 2 & 70 & 8 & 0.0048 \\
2 & 12 & 10 & 26 & 12 & 0.0038 \\
3 & 8 & 8 & 80 & 10 & 0.0020 \\
4 & 4 & 16 & 24 & 15 & 0.0098 \\
5 & 22 & 14 & 08 & 2 & 0.0001 \\
6 & 14 & 2 & 54 & 2 & 0.0013 \\
7 & 4 & 18 & 30 & 2 & 0.0009 \\
8 & 6 & 10 & 60 & 4 & 0.0011 \\
9 & 16 & 14 & 64 & 7 & 0.0005 \\
10 & 20 & 18 & 22 & 13 & 0.0016 \\
11 & 24 & 16 & 114 & 7 & 0.0002 \\
12 & 14 & 12 & 56 & 14 & 0.0015 \\
13 & 14 & 28 & 70 & 2 & 0.0001 \\
14 & 10 & 24 & 52 & 1 & 0.0001 \\
15 & 6 & 2 & 126 & 18 & 0.0119 \\
16 & 20 & 18 & 98 & 4 & 0.0001 \\
17 & 8 & 16 & 46 & 1 & 0.0002 \\
18 & 24 & 14 & 64 & 6 & 0.0003 \\
19 & 8 & 12 & 106 & 14 & 0.0014 \\
20 & 10 & 2 & 102 & 5 & 0.0025 \\
\hline
\end{tabular}

We applied Algorithm 1 to solve the problem and the solution is shown in Table 3. A total of 8 cargo holds were used. The cargo holds carried prefab products that had quite different densities. For instance, cargo hold 1 carried prefab products 15, 5, and 4, in which prefab product 15 had the highest density among the 20 prefab products and prefab product 5 had the lowest density. Moreover, the orientations of many prefab products were changed, i.e., different from the default orientation in Table 2, including prefab products $4,6,13,14$, and 18 .

Table 3. Prefab product loading plan.

\begin{tabular}{cccc}
\hline Truck ID & Prefab Product ID & Coordinates of Centroid & Sizes in Dimensions A, B, and C \\
\hline 1 & 15 & $3,1,63$ & $6,2,126$ \\
& 5 & $17,9,180$ & $22,14,108$ \\
4 & $30,28,242$ & $4,24,16$ \\
\hline 2 & 1 & $6,1,35$ & $12,2,70$ \\
& 13 & $26,9,105$ & $28,14,70$ \\
\hline 3 & 2 & $6,5,13$ & $12,10,26$ \\
& 14 & $24,15,52$ & $24,10,52$ \\
& 20 & $41,21,129$ & $10,2,102$ \\
\hline 4 & 3 & $4,4,40$ & $8,8,80$ \\
& 16 & $18,17,129$ & $20,18,98$ \\
& 10 & $38,35,189$ & $20,18,22$ \\
\hline 5 & 12 & $7,6,28$ & $14,12,56$ \\
& 11 & $26,20,113$ & $24,16,114$ \\
\hline 6 & 19 & $4,6,53$ & $8,12,106$ \\
& 17 & $12,20,129$ & $8,16,46$ \\
& 6 & $17,35,179$ & $2,14,54$ \\
\hline 7 & 8 & $3,5,30$ & $6,10,60$ \\
& 18 & $13,22,92$ & $14,24,64$ \\
& 7 & $22,43,139$ & $4,18,30$ \\
\hline 8 & 9 & $8,7,32$ & $16,14,64$ \\
\hline
\end{tabular}




\section{Discussions}

We have presented a stylized model that captures the key constraints in load planning of prefab products in a cargo hold. There are a few issues that are worth discussion before prefab housing producers, logistics companies, and construction site managers adopt the proposed model.

First, if BIM is used, then the information on the dimensions of the prefab products is available in the BIM system. As a result, the proposed model and algorithm can be integrated into the BIM system to allow ease of use. If BIM is not available, it may be too tedious for planners to manually input the parameters of the model into a program and planners may be reluctant to use the model. In other words, the key success of decision support systems is the availability of data.

Second, we have assumed that the shape of a prefab product is a rectangular prism. In reality, some prefab products have hollows and therefore smaller prefab products can be placed inside bigger prefab products with hollows. This will allow more prefab products to be loaded into a cargo hold. Therefore, a future study is to examine prefab products with more complex shapes. It should be noted that mathematically modeling the complex shapes is very challenging and we expect that artificial intelligence can be adopted to optimize the loading plan of prefab products with complex shapes. Moreover, when the shapes are complex, a BIM system must be available to enable the use of decision support tools.

Third, some prefab products may be fragile and cannot be placed under other prefab products. Moreover, the area of contact between two prefab products with one on top of the other cannot be too small. These types of practical constraints should be incorporated, otherwise the generated loading plan has to be visually inspected by an experienced planner.

Fourth, we have assumed that all the prefab products come from the same factory. In practice, they can come from several factories, either factories of the same company or different companies. In that case, a cargo hold may have to visit more than factory to transport prefab products to the construction site. As a result, we will have to jointly optimize the assignment of prefab products to cargo holds, the route of the cargo holds, and the loading plan of prefab products in the cargo holds. This joint optimization problem is a worthwhile research topic.

\section{Conclusions}

Prefab is a method for construction borrowed from the manufacturing industry. Prefab products must be transported from factory to construction sites. This study has proposed a prefab product loading planning problem in which we decided which prefab products to load into the same cargo hold and how to store them in the cargo hold in order to use the least number of cargo holds to transport the prefab products. We proposed a large-scale integer optimization model for the problem and developed a heuristic to address the problem. A case study was carried out to demonstrate the applicability of the proposed model. We find that the cargo holds carry prefab products that have quite different densities. Moreover, the orientations of many prefab products are changed. To the best of our knowledge, we are the first to propose the prefab product load planning problem, which contributes to the literature on prefab construction. We hope that our study can contribute to the construction industry by reducing the number of cargo hold trips and thereby reducing the costs and emissions.

Author Contributions: Conceptualization, W.Y., H.W. and R.P.; methodology, W.Y. and H.W.; writing—original draft preparation, W.Y.; writing - review and editing, W.Y. and R.P.; supervision, R.P. All authors have read and agreed to the published version of the manuscript.

Funding: This research received no external funding.

Conflicts of Interest: The authors declare no conflict of interest. 


\section{References}

1. Xiao, Y.; Zhao, J.; Sun, S.; Guo, L.; Axmacher, J.; Sang, W. Sustainability Dynamics of Traditional Villages: A Case Study in Qiannan Prefecture, Guizhou, China. Sustainability 2019, 12, 314. [CrossRef]

2. Zhang, L.; Chu, Z.; Song, H. Understanding the Relation between BIM Application Behavior and Sustainable Construction: A Case Study in China. Sustainability 2020, 12, 306. [CrossRef]

3. Jaillon, L.; Poon, C.S. Design issues of using prefabrication in Hong Kong building construction. Constr. Manag. Econ. 2010, 28, 1025-1042. [CrossRef]

4. Lu, W.; Yuan, H. Investigating waste reduction potential in the upstream processes of offshore prefabrication construction. Renew. Sustain. Energy Rev. 2013, 28, 804-811. [CrossRef]

5. Zhong, R.Y.; Peng, Y.; Xue, F.; Fang, J.; Zou, W.; Luo, H.; Ng, S.T.; Lu, W.; Shen, G.Q.P.; Huang, G.Q. Prefabricated construction enabled by the Internet-of-Things. Autom. Constr. 2017, 76, 59-70. [CrossRef]

6. Zhu, H.; Hong, J.; Shen, G.Q.; Mao, C.; Zhang, H.; Li, Z. The exploration of the life-cycle energy saving potential for using prefabrication in residential buildings in China. Energy Build. 2018, 166, 561-570. [CrossRef]

7. Lederer, J.; Gassner, A.; Keringer, F.; Mollay, U.; Schremmer, C.; Fellner, J. Material Flows and Stocks in the Urban Building Sector: A Case Study from Vienna for the Years 1990-2015. Sustainability 2020, 12, 300. [CrossRef]

8. Hong, J.; Shen, G.Q.; Li, Z.; Zhang, B.; Zhang, W. Barriers to promoting prefabricated construction in China: A cost-benefit analysis. J. Clean. Prod. 2018, 172, 649-660. [CrossRef]

9. Chen, Y.; Okudan, G.E.; Riley, D.R. Decision support for construction method selection in concrete buildings: Prefabrication adoption and optimization. Autom. Constr. 2010, 19, 665-675. [CrossRef]

10. Li, C.Z.; Hong, J.; Xue, F.; Shen, G.Q.; Xu, X.; Luo, L. SWOT analysis and Internet of Things-enabled platform for prefabrication housing production in Hong Kong. Habitat Int. 2016, 57, 74-87. [CrossRef]

11. Chang, Y.; Li, X.; Masanet, E.; Zhang, L.; Huang, Z.; Ries, R. Unlocking the green opportunity for prefabricated buildings and construction in China. Resour. Conserv. Recycl. 2018, 139, 259-261. [CrossRef]

12. Lu, W.; Chen, K.; Xue, F.; Pan, W. Searching for an optimal level of prefabrication in construction: An analytical framework. J. Clean. Prod. 2018, 201, 236-245. [CrossRef]

13. Zhang, W.; Lee, M.W.; Jaillon, L.; Poon, C.S. The hindrance to using prefabrication in Hong Kong's building industry. J. Clean. Prod. 2018, 204, 70-81. [CrossRef]

14. Tam, V.W.; Tam, C.M.; Ng, W.C. On prefabrication implementation for different project types and procurement methods in Hong Kong. J. Eng. Des. Technol. 2007, 5, 68-80. [CrossRef]

15. Tam, V.W.; Fung, I.W.; Sing, M.C.; Ogunlana, S.O. Best practice of prefabrication implementation in the Hong Kong public and private sectors. J. Clean. Prod. 2015, 109, 216-231. [CrossRef]

16. Li, C.Z.; Shen, G.Q.; Xu, X.; Xue, F.; Sommer, L.; Luo, L. Schedule risk modeling in prefabrication housing production. J. Clean. Prod. 2017, 153, 692-706. [CrossRef]

17. Li, X.; Shen, G.Q.; Wu, P.; Fan, H.; Wu, H.; Teng, Y. RBL-PHP: Simulation of lean construction and information technologies for prefabrication housing production. J. Manag. Eng. 2017, 34, 04017053. [CrossRef]

18. Wong, P.S.; Zwar, C.; Gharaie, E. Examining the drivers and states of organizational change for greater use of prefabrication in construction projects. J. Constr. Eng. Manag. 2017, 143, 04017020. [CrossRef]

19. Chen, K.; Xu, G.; Xue, F.; Zhong, R.Y.; Liu, D.; Lu, W. A physical internet-enabled building information modelling system for prefabricated construction. Int. J. Comput. Integr. Manuf. 2018, 31, 349-361. [CrossRef]

20. Li, C.Z.; Xue, F.; Li, X.; Hong, J.; Shen, G.Q. An Internet of Things-enabled BIM platform for on-site assembly services in prefabricated construction. Autom. Constr. 2018, 89, 146-161. [CrossRef]

21. Li, C.Z.; Xu, X.; Shen, G.Q.; Fan, C.; Li, X.; Hong, J. A model for simulating schedule risks in prefabrication housing production: A case study of six-day cycle assembly activities in Hong Kong. J. Clean. Prod. 2018, 185, 366-381. [CrossRef]

22. Liu, J.; Lu, M. Robust dual-level optimization framework for resource-constrained multiproject scheduling for a prefabrication facility in construction. J. Comput. Civ. Eng. 2018, 33, 04018067. [CrossRef]

23. Tan, T.; Chen, K.; Xue, F.; Lu, W. Barriers to Building Information Modeling (BIM) implementation in China's prefabricated construction: An interpretive structural modeling (ISM) approach. J. Clean. Prod. 2019, 219, 949-959. [CrossRef] 
24. Tommelein, I.D.; Li, A. Just-in-time concrete delivery: Mapping alternatives for vertical supply chain integration. In Proceedings of the 7th Annual Conference on Lean Construction, Berkeley, CA, USA, 7 July 1999; pp. 97-108.

25. Pheng, L.S.; Chuan, C.J. Just-in-time management of precast concrete components. J. Constr. Eng. Manag. 2001, 127, 494-501. [CrossRef]

26. Niu, Y.; Lu, W.; Liu, D.; Chen, K.; Anumba, C.; Huang, G.G. An SCO-enabled logistics and supply chain-management system in construction. J. Constr. Eng. Manag. 2016, 143, 04016103. [CrossRef]

27. Hsu, P.Y.; Angeloudis, P.; Aurisicchio, M. Optimal logistics planning for modular construction using two-stage stochastic programming. Autom. Constr. 2018, 94, 47-61. [CrossRef]

28. Liu, Y.; Li, Y.; Hu, L. Departure time and route choices in bottleneck equilibrium under risk and ambiguity. Transp. Res. Part B Methodol. 2018, 117, 774-793. [CrossRef]

29. Liu, Y.; Nie, Y.M. A credit-based congestion management scheme in general two-mode networks with multiclass users. Netw. Spat. Econ. 2017, 17, 681-711. [CrossRef]

30. Liu, P.; Liu, Y. Optimal information provision at bottleneck equilibrium with risk-averse travelers. Transp. Res. Rec. 2018, 2672, 69-78. [CrossRef]

31. Yu, G.; Haskell, W.B.; Liu, Y. Resilient facility location against the risk of disruptions. Transp. Res. Part B Methodol. 2017, 104, 82-105. [CrossRef]

32. Wu, L.; Yang, D.; Wang, S.; Yuan, Y. Evacuating offshore working barges from a land reclamation site in storm emergencies. Transp. Res. Part E Logist. Transp. Rev. 2020, 137, 101902. [CrossRef]

33. Yan, R.; Wang, S.; Du, Y. Development of a two-stage ship fuel consumption prediction and reduction model for a dry bulk ship. Transp. Res. Part E Logist. Transp. Rev. 2020, 138, 101930. [CrossRef]

34. Zhen, L.; Hu, Y.; Wang, S.; Laporte, G.; Wu, Y. Fleet deployment and demand fulfillment for container shipping liners. Transp. Res. Part B Methodol. 2019, 120, 15-32. [CrossRef]

35. Li, Y.; Liu, Y.; Xie, J. A path-based equilibrium model for ridesharing matching. Transp. Res. Part B Methodol. 2020, 138, 373-405. [CrossRef]

36. Wang, S.; Yan, R.; Qu, X. Development of a non-parametric classifier: Effective identification, algorithm, and applications in port state control for maritime transportation. Transp. Res. Part B Methodol. 2019, 128, 129-157. [CrossRef]

37. Wu, L.; Wang, S. The shore power deployment problem for maritime transportation. Transp. Res. Part E Logist. Transp. Rev. 2020, 135, 101883. [CrossRef]

38. Li, F.; Yang, D.; Wang, S.; Weng, J. Ship routing and scheduling problem for steel plants cluster alongside the Yangtze River. Transp. Res. Part E Logist. Transp. Rev. 2019, 122, 198-210. [CrossRef]

39. Du, Y.; Meng, Q.; Wang, S.; Kuang, H. Two-phase optimal solutions for ship speed and trim optimization over a voyage using voyage report data. Transp. Res. Part B Methodol. 2019, 122, 88-114. [CrossRef]

40. Zhen, L.; Wu, Y.; Wang, S.; Laporte, G. Green technology adoption for fleet deployment in a shipping network. Transp. Res. Part B Methodol. 2020, 139, 388-410. [CrossRef]

Publisher's Note: MDPI stays neutral with regard to jurisdictional claims in published maps and institutional affiliations.

(C) 2020 by the authors. Licensee MDPI, Basel, Switzerland. This article is an open access article distributed under the terms and conditions of the Creative Commons Attribution (CC BY) license (http://creativecommons.org/licenses/by/4.0/). 